https://doi.org/10.48009/1_iis_2014_390-398

Issues in Information Systems

Volume 15, Issue I, pp. 390-398, 2014

\title{
VOLUNTEER ONLINE STUDENT-LED TECHNOLOGY BASED PROJECTS: BENEFITS AND LIMITATIONS
}

\author{
Dr. Tina Burton, Kaplan University, tburton@kaplan.edu \\ Dr. Rhonda Chicone, Kaplan University, rchicone@kaplan.edu
}

\begin{abstract}
Student-led information systems projects allow participants to gain real-world experience, provide a service or product to the community, and help the learners to develop skills in many areas including project management, teamwork, database design, web development, and network security, among others. With student-led projects that are not designed to result in an academic grade or financial gain, student participation can be inconsistent. Although the benefits are significant, participants lose motivation and projects can fail. This study explores the participation within a student-led project that involved the creation of a database driven, web-based system which provides a valuable service to small businesses, free of charge.
\end{abstract}

Keywords: Students, Projects, Externships, Real-World Experience, Motivation

\section{INTRODUCTION}

Students in pursuit of their degree often seek and require professional experience to augment their education in order to be successful in the workplace. Absent professional employment in their field, they often are in need of other prospects for gaining this experience. Many schools offer internship/externship courses for their students to provide this type of opportunity; in some cases the work performed is on-site with potential employers in the students' geographic area and industry. For online students, these types of on-site opportunities can be limited. In these cases, online students may have the opportunity to work remotely and complete projects in a virtual environment. As with the on-site positions, these virtual positions are voluntary and benefit both the students and the associated organizations that sponsor the projects. Unfortunately, student participation can sometimes wane as the project continues, producing less than desirable project outcomes and a lack of student benefit. A variety of factors may contribute to this diminishing interest on behalf of the students, in spite of the benefits they sacrifice that can be critical to their success.

Kaplan University, in collaboration with Random Hacks of Kindness, initiated a product idea in May 2013 as to fill a need in the global market. The idea was to create a free web-based system that could be used by small businesses that didn't have an Information Technology (IT) staff and/or IT knowledge. The system would be easy to use and would help small businesses solve their IT related issues by presenting easy to follow step-by-step instructions. Student involvement included taking the idea and bringing it to market. Administration and faculty promoted the idea, initiating student engagement. Students named the system My IT Consultant ${ }^{\mathrm{TM}}$ (myitconsultant.org) and version 1.0 was launched in October of 2013. The system is Linux based and was constructed using HTML5, JavaScript, Ajax, PHP and MySQL. Version 2.0 will launch in August 2014 to include an administration subsystem and the addition of more solutions to small business IT problems.

\section{BACKGROUND}

\section{Student-Led Projects}

In general, student-led academic projects provide no monetary compensation or academic credit to the participants. Given this condition, the question becomes, what motivates some students to 'volunteer' to be part of the project, while others decline the opportunity to serve and lead? As one study indicates, volunteerism among students is often as high as $63 \%$ for formal volunteerism; external organizations find that higher education students are ideal candidates for their agencies to pursue [2]. Of the students volunteering, $95 \%$ state that they are motivated to help others or improve things in their community. The volunteers also report that the activities, even though unpaid, greatly impact their own personal development, skills and employability. In this particular study, $51 \%$ of the recent graduates reported that the volunteering effort helped them to gain paid employment positions. Linking the 


\section{Issues in Information Systems}

Volume 15, Issue I, pp. 390-398, 2014

volunteering efforts to particular areas of study even further enhanced the benefit and desirability of the activities [2].

Clearly the participation in these types of voluntary endeavors is inspired by a variety of both intrinsic and extrinsic factors. The debate as to which factors most effect student participation and persistence is a primary focus of this study. Initially, theories related to intrinsic and extrinsic theories are explored and related to the results of the student survey, as a means to understand their relationship. Subsequently the data collected is reviewed and summarized for interpretation.

\section{Project-Based Learning}

The benefits to students in project-based learning are significant. The projects tend to be learner centered and students are able to hand-pick their areas of specialization and interest within the project. Although students often need guidance to set goals for the project, they are enabled to drive the day to day tasks and therefore achieve a greater understanding of how their tasks contribute to the project as a whole and how their contributions impact the overall success of the project. Generally a higher level of intrinsic motivation is observed and required for the success of project-based learning [9].

The benefits to students in these project-based learning environments also include a high level of collaboration and cooperative learning that translates well to workplace projects they will face in their careers. This type of learning generally results in the presentation of a product or significant deliverable; which also aligns with workplace expectations. One of the greatest benefits for students in this type of learning is that they learn by 'doing' vs. observing. This type of learning can be more challenging but tends to produce higher-order skill development [10].

This type of project-based learning provides benefits to the faculty and educational institutions as well. The content that results from the activities has an authentic purpose and can be assessed more explicitly as the deliverable provides a function and value to the institution or an external entity. The instructor role in this type of learning is less rigorous and is more that of a mentor and guide than a teacher. The formative and summative evaluation opportunities are plentiful throughout the project [10].

\section{Intrinsic and Extrinsic Motivation}

Several historical theories can be cited that address both intrinsic and extrinsic motivation in the workplace and in academic settings. Herzberg's Two-Factor Theory addressed both intrinsic factors and extrinsic factors that have an effect on job satisfaction and motivation in the workplace. He theorized that extrinsic factors such as working conditions or pay would not motivate; however, he did argue that the absence of such factors can decrease motivation [6]. That may be indicative of the loss of student participation in projects that are not compensated monetarily or with course credit. Herzberg also proposed that intrinsic factors such as challenging work and a sense of personal value or growth could produce some of the highest levels of motivation in employees [6], which may account for the motivation for participation within a student-led project.

The second theory that addressed intrinsic vs. extrinsic motivation is the Cognitive Evaluation Theory. The followers of this theory believe that an individual evaluates a task based on its value in meeting the person's need to feel competent. If the task seems doable, the person will be intrinsically motivated to complete the task and will not require additional extrinsic motivation. How powerful this intrinsic motivation can be is determined by the person's internal locus of control, which is determined by how 'in control' he feels about behaviors. People with a stronger external locus of control, will feel that the environment has a greater control over behaviors than they do themselves. [3]. This theory may support the thought that some students are intrinsically motivated to work on projects they know they will succeed at, while others will not find motivation in this manner and must instead final an external factor to drive their persistence.

The third theory that addresses how intrinsic motivation can be affected by extrinsic factors is the SelfDetermination Theory. Based on this theory, although intrinsic factors tend to be more powerful [7], it is noted that external factors can often displace intrinsic motivation [3]. In one study, [8] it was found that when individuals earned rewards for tasks they enjoyed, they would soon lose interest in doing the same task for no reward. In this 


\section{Issues in Information Systems \\ Volume 15, Issue I, pp. 390-398, 2014}

way, extrinsic factors can ultimately make a previously desirable task less enjoyable. This may be seen in the student that initially found serving on the project intrinsically rewarding and later lost interest due to the lack of ongoing external reward.

In a study of college students it was found that they are often intrinsically motivated and develop a high regard for learning, in spite of the lack of external rewards; in this case, the intrinsic overcomes the lack of extrinsic rewards [8]. A second study also provides that when considering motivation as an internal state, it can arouse individuals and guide them in a direction which keeps them actively engaged in tasks that help them succeed [11]. This same intrinsic motivation can help determine if a student succeeds when faced with a more challenging task; this motivation enables cognitive and behavioral processes that may be necessary for an individual's learning to take place [11]. These theories certainly support the fact that students who are intrinsically motivated to participate in student-led projects may be more likely to persist. Clearly, students who are intrinsically motivated may have some advantage over others because they find academic tasks pleasurable and stimulating [12].

Arguably there are benefits to extrinsic motivating factors as well. Students who are motivated extrinsically are driven by recognition, grades, and competition with others [9]. Oftentimes extrinsic motivation emphasizes the social side of learning; the goal can be merely recognition for demonstrating knowledge rather than actual achievement [9]. One weakness to extrinsic motivation may be that students cease efforts or minimize their effort when external rewards are withheld [9]. Students participating in student-led projects who possess this kind of motivation may have waning interest as the spotlight on the project fades.

Generally when evaluating the motivation for pursuing a higher level of education or professional appointment, achievement theories may apply. Two specific types of achievement-related attitudes are task-involvement and egoinvolvement. With task-involvement the individual is motivated by obtaining new talents and mastering new theories. In contrast, ego-involvement attitudes arise from students that are driven by their yearning to achieve superior abilities [5]. Both task and ego involvement aspects were detected in this study of project participants.

The motivational theories summarized in this section provide an essential overview of how both internal and external factors may affect behavior, achievement, and sustained performance. Although the theorists deliberate as to how each element may affect the motivation of students, all seem to agree that both intrinsic and extrinsic factors have a relationship with all types of motivation and its associated behavior. The findings in this study indicate a similar mix of both intrinsic and extrinsic factors as they contributed to persistence in the student-led project that this study explores.

\section{PROBLEM STATEMENT}

Students provided with an opportunity to gain real-world experience, while serving on student-led project teams, often lack the motivation to persist on those projects and are unable to reap the significant benefits of completing the project successfully.

\section{RESEARCH METHODOLOGY}

A qualitative, phenomenological methodology was chosen for this study, as the intent was to determine the lived experience of some recent student participants, in an online student-led technology based project.

Our research centered upon the following research questions:

What intrinsic factors motivate students to persist on student-led project teams?

What extrinsic factors motivate students to persist on student-led project teams?

To determine these factors, an online survey was given to students who were invited and participated on the My IT Consultant ${ }^{\mathrm{TM}}$ project. They were asked to identify the elements, both internally and externally that influenced their decision to participate, persist, and/or resign from the student-led project opportunity they were presented with at Kaplan University. 


\section{FINDINGS}

\section{Participant Demographics}

Over 25 current Kaplan University students and alumni were invited to join the project team at its inception and throughout the project. Not all those invited were able to participate through the initial phases of the project. The demographics of the participants in the study varied and included both employed and unemployed students and a variety of age ranges and levels of experience. Surprisingly those most interested in participating in the project were already in full-time employment positions. As indicated in Figure 1,64\% of the participants were already employed and working over 40 hours a week; which further indicates their level of motivation for overachieving while pursuing their academic credentials.

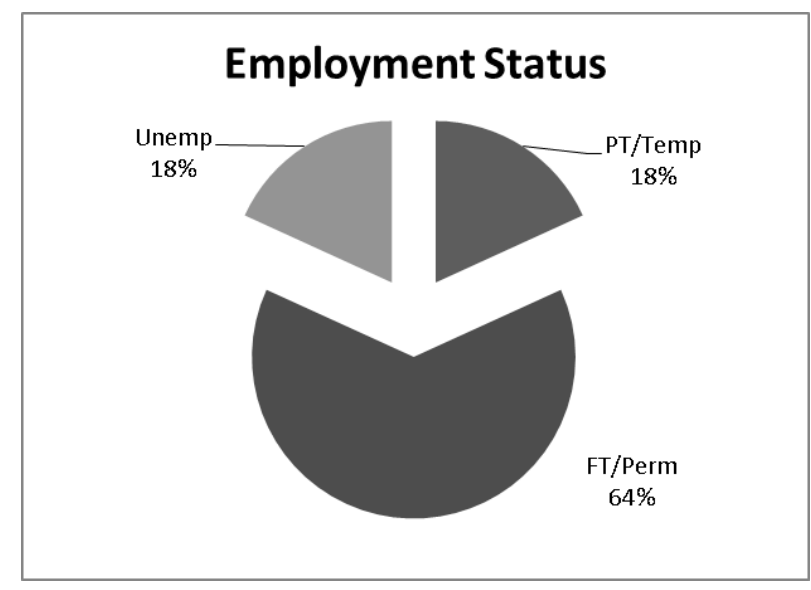

Figure 1: Employment status (additional categories of PT/Perm and FT/Temp applied to no participants)

Participants were also asked their age range and the data provided is indicated in Figure 2. Although the age ranges were fairly representative of the School of IT demographics overall, a significant number of participants were in the 45 or older category, which was also surprising to the researchers as it would be assumed that the participants in the younger age categories would be more in need of experience to add to their resume.

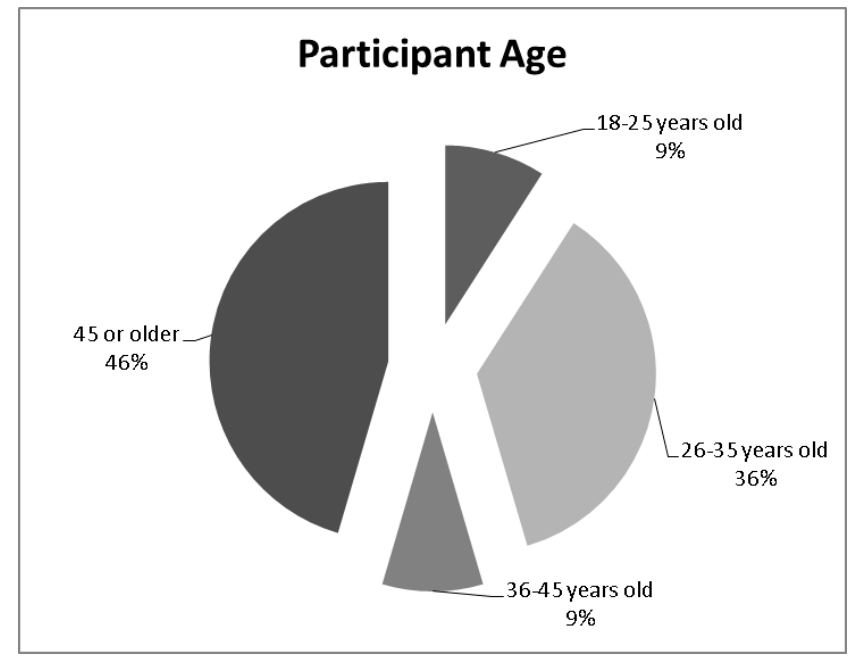

Figure 2: Age Range (all age range categories were represented)

The project was open to all of the online university's information technology students, including alumni. In some cases the students were approaching graduation when they entered the project and elected to stay on as alumni 


\section{Issues in Information Systems \\ Volume 15, Issue I, pp. 390-398, 2014}

participants. The highest percentage of participants was from the undergraduate program and included students in a variety of Associates and Bachelor of Information Technology degree program specializations including Web Development, Information Security and Assurance, Information Systems Management, Project Management, and Networking Administration. One graduate is now in law school. Figure 3 indicates the percentage from each category.

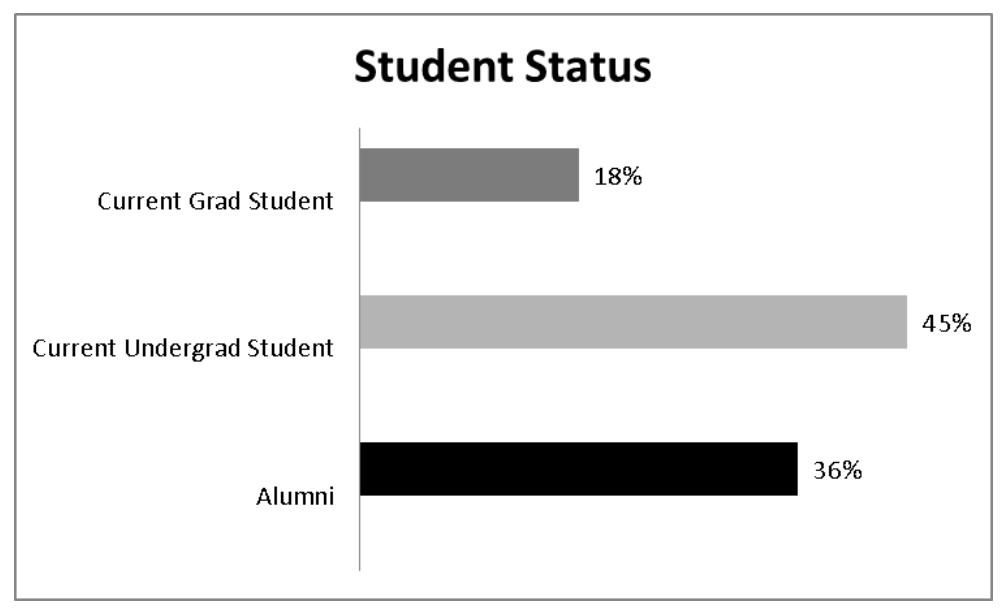

Figure 3: Student Status (alumni group includes graduates from both the AA and BSIT programs)

\section{Student Motivation for Pursuing an Information Technology Degree}

The participants in the study were asked to share what motivated them to pursue an IT degree vs. some other area of concentration. The answers were quite varied with a long-held personal interest or affinity to technology being the most common response. Some participants reported that the growing IT industry and availability of jobs was their motivation, while a few others reported that their parents' experience and advice guided them towards IT as a career choice.

\section{Student Persistence}

The level of persistence in the project varied greatly as well as the other demographic factors. The majority of students who responded to the survey did persist throughout the ongoing project although these overall persistence results may not indicate a true figure of those who started with the project but did not persist as they may have declined to complete the survey at a higher rate. Figure 4 below indicates the percentage of students who persisted into the current project phase from the beginning (July 2013) and those that spent less time participating on the project. The students who participated only in v1.0 would have contributed approximately four months of their time to the project. Version 2.0 of the project launched in October of 2013 and is scheduled to complete in August 2014.

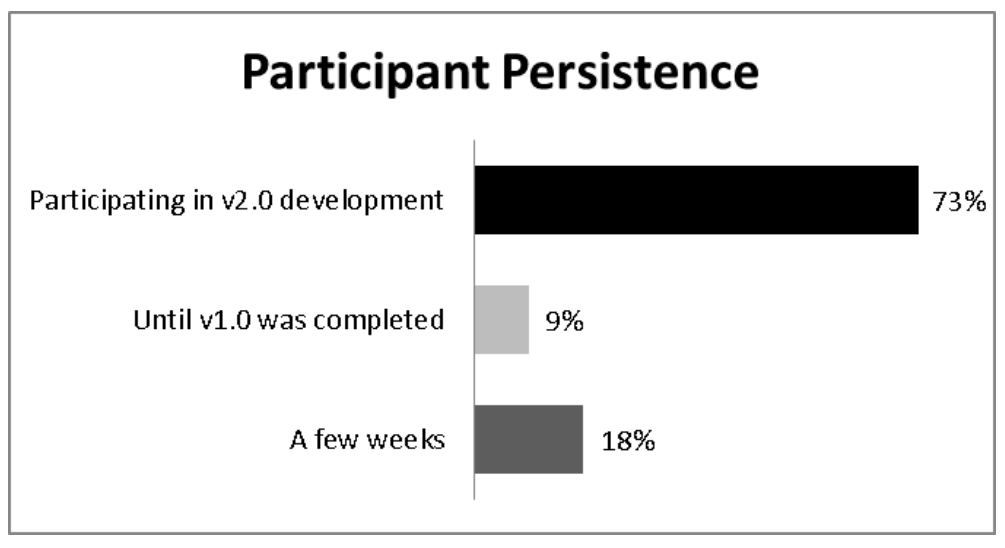

Figure 4: Student Persistence on the Project 


\section{Participant Roles and Time Commitment}

Students who participated on the project held a variety of roles and their individual time commitments varied based on their roles and their own availability. Some of the roles/tasks reported by the participants include: project management, software development (HTML5, PHP, JavaScript, AJAX) and MySQL database development, solutions development (generating common IT problems and solutions to the problems), user interface design, media development, and information security expertise. The experience levels and opportunities for contributing were quite varied but all participants were given a role and their time was valued greatly by the team. Figure 5 indicates the time spent by the participants during the time they were part of the team.

\section{Time Spent per Week}

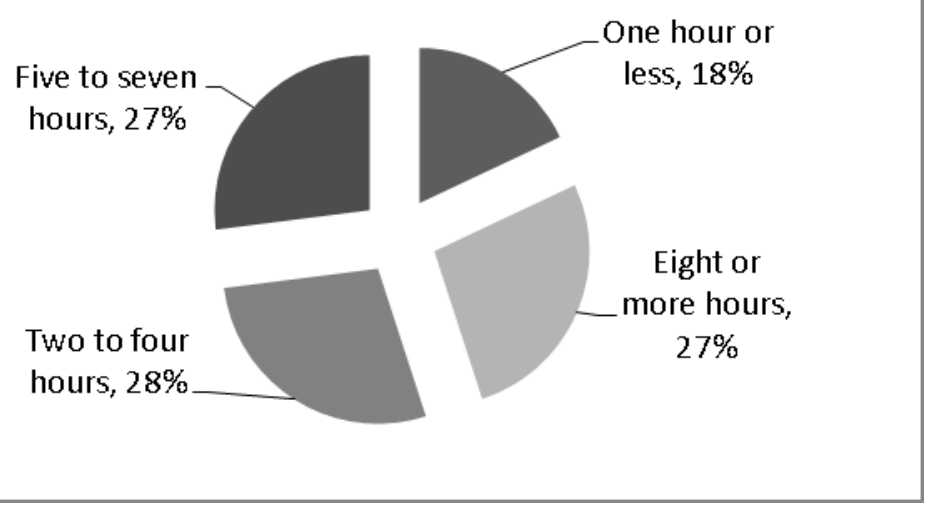

Figure 5: Time spent working on the project

\section{Intrinsic Motivating Factors Observed}

The intrinsic motivating factors reported by the participants varied with some commonalities to note. Table 1 lists the factors in order of prevalence among the participants. Although some responses may not seem totally intrinsic, they were identified as such by the participants.

Table 1: Most common intrinsic factors noted by participants

\begin{tabular}{|l|}
\hline The desire to help people solve problems \\
\hline Doing something related to career to further enhance employability \\
\hline Opportunity to use talents to better a project and its participants \\
\hline Test ability to work with other people \\
\hline Potential to teach and to learn \\
\hline Having a feeling of belonging \\
\hline Drive to succeed and pride in creating something great \\
\hline To experience being in a group of IT professionals \\
\hline
\end{tabular}

\section{Extrinsic Motivating Factors Observed}

Table 2 lists the common extrinsic motivating factors that influenced the participants to join and persist. As indicated previously, the majority of those completing the survey did persist at least through phase one of the project. Approximately $50 \%$ of all students who were invited and participated even for a short time completed the survey; however, those that did not persist or were invited and did not persist beyond a few weeks, also did not all participate in the survey. The faculty project sponsor did get some emails throughout the project from members who felt the need to quit the project and their prevailing rationale was time constraints and personal factors that led to 


\section{Issues in Information Systems \\ Volume 15, Issue I, pp. 390-398, 2014}

their inability to persist with the project. Even those that found it necessary to quit did acknowledge the value of the project and their participation.

Table 2: Most common extrinsic factors noted by participants Gain documented work experience for resume and for self-confidence Master skills for working on a virtual team successfully Being able to help others (small businesses) Encouragement from friends and professors

Table 2 clearly indicates the expected benefits for a student-led technology project. Any hands-on/real-life experience that can be added to a resume or a student's documented skill set provides a significant benefit. Employers today agree that in some cases "real-world experience is the only thing standing between some graduates and their dream jobs" [1]. This study's intent was also to assess why students did not persist and the only evidence to explain this phenomenon is the aforementioned email resignations; which indicate students had a desire to participate but life events and time constraints made it impossible.

\section{Benefits Derived}

Participants were asked to share the greatest benefits from their participation on the project. The combined results are shown in Table 3. In most cases, the benefits noted are similar to the extrinsic motivating factors, which indicate that students mostly derived the benefits they expected and desired.

Table 3: Benefits gained from the project experience

\begin{tabular}{|l|}
\hline Gaining real world experience \\
\hline Additions to resume/skill set \\
\hline Learning to work with people and communicate with people who are not face to face with you \\
\hline The extra requirements to plan and execute a project based upon varying participation levels \\
\hline Learning from fellow teammates, such as all the work that goes in to developing a large database \\
\hline Learning that other people have their own roles to fulfill \\
\hline Satisfaction of knowing that we built something great, and the teamwork that we had to get us there \\
\hline Learning and meeting people \\
\hline
\end{tabular}

The faculty sponsor's observation of the project team also indicated that the participants became skilled virtual workers in that they effectively employed tools such as Google Hangouts and Adobe Connect to facilitate project meetings and create effective working relationships between team members. As many employers now require, working virtually and with virtual teams effectively is essential for successful information technology project implementations [1].

\section{Benefits Expected and Not Derived}

Participants were also asked what benefits they expected to get from the project and were not yet achieved. The most prevalent answer, as indicated in Table 4, is 'none'. The benefits expected were generally gained by the participants, with just a few exceptions as noted in Table 4.

Table 4: Benefits expected and not derived

\begin{tabular}{|l|}
\hline None so far \\
\hline Mastering project management skills; opportunity diminished as project team lost members \\
\hline Unable to secure a job; project skills gained but jobs are hard to find \\
\hline More in depth learning of copier/printer issues explored \\
\hline
\end{tabular}




\section{Suggestions for Future Project Participants}

In the final question of the survey, participants were asked to share thoughts for future project team members. The suggestions were varied and insightful for prospective members. Table 5 lists the recommendations offered.

Table 5: Suggestions for future members

\begin{tabular}{|l|}
\hline Come in with an open mind and be willing to help out wherever help is needed \\
\hline $\begin{array}{l}\text { A perfect opportunity to work with other students and see how projects can go from just ideas to a functioning } \\
\text { product }\end{array}$ \\
\hline Dedication and communication are key \\
\hline Take ownership of the project and learn new things to make it, and you, better \\
\hline Ask for help; everyone is very nice and happy to help \\
\hline Very friendly and motivational experience, one that I would take again in a second, given the opportunity \\
\hline $\begin{array}{l}\text { The role that you played during the project was dependent upon how much hands-on time and experience you } \\
\text { gained but it was worth it }\end{array}$ \\
\hline Get involved if you can; it is a great project with a smart team of people \\
\hline Where you can learn a lot, and gain real world experience \\
\hline $\begin{array}{l}\text { It's a project about helping small businesses solve technological problems; there isn't really a trusted resource on } \\
\text { the internet that allows a small business owner to make educated choices about their own company's } \\
\text { technological needs }\end{array}$ \\
\hline Do it, and make the time; it is very rewarding \\
\hline Join and learn \\
\hline I would highly recommend this project to any student studying IT or a related field \\
\hline $\begin{array}{l}\text { This is a good work experience and gives the student a more in depth view of what a web based data driven } \\
\text { system looks like }\end{array}$ \\
\hline
\end{tabular}

\section{CONCLUSIONS}

Several of the project team members, who continue with their efforts today, even beyond graduation in some cases, have a vision to continually improve the product using agile software process methodologies. They would like to make the free web based product an offering not only to small businesses, but also to the public at large. They have hopes to grow the service to be able to provide information technology technician/consultant referrals on demand using location-based application programming interfaces (APIs) to serve the communities that lack this expertise. A long-term goal is to localize the product in other languages to reach areas outside of the United States. In addition to their visions for the product growth, individual team members have been successful in gaining employment based on their experience with the project; one recent graduate secured a position as an Associate Software Engineer immediately following graduation and her discussion during the interview about the product and her role within the project team provided the employer with confidence in her abilities.

This study and the participants' responses support the concept that student-led information technology projects can be rewarding and beneficial to students and the community, as well to a university as a whole. While not all participants were able to persist and achieve the full range of benefits, each member expressed a positive effect from the experience. As the project continues into its second phase, data on the experience will be collected and shared with the university and its constituents. 


\section{REFERENCES}

1. Baker, T. (2013, August 14). Why gaining work experience is more important than your degree. Brazen Life: Lifestyle and Career Blog, Huffington Post. Retrieved from http://www.huffingtonpost.com/brazenlife/why-gaining-work-experien_b_3750261.html

2. Brewis, G., Russell, J., \& Holdsworth, C. (2010). Bursting the bubble: Students, volunteering, and the community research summary. Retrieved from https://www.publicengagement.ac.uk/sites/default/files/NCCPE\%20-\%20Bursting\%20the\%20bubble.pdf

3. Deci, E. L., \& Ryan, R. M. (1985). Intrinsic motivation and self-determination in human behavior. New York: Plenum Press

4. Gates, B. (1995). The road ahead. New York, NY: Viking Penguin Group.

5. Gendolla, G.; Brinkmann, K., \& Scheder, D. (2008, September). Ego involvement moderates the assimilation effect of affective expectations. Motivation \& Emotion, 32(3), 213-220.

6. Herzberg, F., Mausner, B., \& Snyderman, B. (1959). The motivation to work. New York: Wiley.

7. Lei, S. A. (2010, June). Intrinsic and extrinsic motivation: Evaluating benefits and drawbacks from college instructors' perspectives. Journal of Instructional Psychology, 37, (2).

8. Lepper, M. R., Greene, D., \& Nisbett, R. E. (1973). Undermining children's intrinsic interest with extrinsic rewards: A test of the "over justification" hypothesis. Journal of Personality and Social Psychology, 28, 129-137.

9. Lynch, D. J. (2010, December). Motivational beliefs and learning strategies as predictors of academic performance in college physics. College Student Journal, 44(4), 920-927.

10. Moursund, D. (2006). "Project-Based Learning". Retrieved from http://darkwing.uoregon.edu/ moursund/Math/pbl.htm

11. Ormrod, J.E. (2008). Human learning. (6th ed.). Upper Saddle River, NJ: Pearson/Prentice Hall.

12. Schunk, D. H., Pintrich, P.R., \& Meece, J. L. (2008). Motivation in education: Theory, research and applications (3rd ed.). Upper Saddle River, NJ: Pearson/Merrill. 